\title{
Muscle damage occurring in wheelchair sports people
}

\author{
M Ide ${ }^{1}$, H Ogata $^{2}$, M Kobayashi ${ }^{2}$ and F Wada ${ }^{2}$ \\ ${ }^{1}$ Department of Rehabilitation Medicine, Kyushu Rosai Hospital, Kuzuharatakamatsu 1-3-1, Kokuraminami ku, \\ Kitakyushu \#800-02, Japan; ${ }^{2}$ Rehabilitation Medicine, University of Occupational and Environmental Health, \\ Iseigaoka 1-1, Yahatanishi ku, Kitakyushu \#807, Japan
}

\begin{abstract}
Seven college-age healthy men exercised on a wheelchair treadmill to evaluate muscle damage that may occur from wheelchair propulsion. An experimental model in which a participant performs up-hill running in a wheelchair was prepared. Plasma creatinekinase (CK), myoglobin $(\mathrm{Mb})$ and lactatedehydrogenase $(\mathrm{LDH})$ were measured as parameters. Blood samples were taken pre-, immediately after-, $24 \mathrm{~h}$ after- and $72 \mathrm{~h}$ after the exercise. All of these parameters significantly increased after the exercise, but their time-courses were apparently varied. It is concluded that wheelchair propulsion causes muscle damage in certain situations such as up-hill running.
\end{abstract}

Keywords: muscle damage; wheelchair propulsion; creatinekinase (CK); myoglobin (Mb); lactatedehydrogenase (LDH)

\section{Introduction}

Temporal muscle damage occurred in those participating in sports activities and physical exercise, and has been discussed by many researchers. Triathalon and marathon races appeared to be the most frequently discussed sports activities. ${ }^{1-3}$ In laboratory conditions, severe exercise involving the elbow flexors has been commonly studied. ${ }^{4-7}$ Delayed onset muscle soreness (DOMS) 8,9 and maximum voluntary contraction ${ }^{4,6}$ were widely evaluated as non-invasive parameters. For invasive parameters, not many authors have used muscle biopsies and histology. ${ }^{10}$ Many researchers have carried out blood sampling, measuring several parameters: ${ }^{1,3,4,6,9,11}$ enzyme activities such as creatinekinase $(\mathrm{CK})$ or lactatedehydrogenase $(\mathrm{LDH})$, myoglobin $\mathrm{Mb})$ content appeared to be the most reliable parameters.

The wheelchair is the inevitable vehicle for seriously physically handicapped individuals who have lost their normal mobility. It is well known that wheelchair propulsion requires less energy consumption than does the use of crutches and an orthosis for gait, but rehabilitation professionals must always be concerned about the possibility of muscle fatigue from wheelchair propulsion by a handicapped person. ${ }^{12}$

The purpose of this study is (1) to establish an experimental wheelchair propulsion model in which muscle fatigue can be clearly observed, and (2) to evaluate the muscle fatigue occurring in the model by haematological studies.

Correspondence: M Ide

\section{Subjects}

Seven healthy male college students were recruited for this study. All participated in some sports activities occasionally, however severe physical work was prohibited during the time of this study. Written informed consent was obtained at each experimental session.

Mean $( \pm \mathrm{SD})$ age of participants was $23.9 \pm 2.0$ years (21 to 26 years). Anthropometric measurements of each subject were done to provide a physical description of the subjects. The average $( \pm S D)$ of each measurements were: height $171.6+4.6 \mathrm{~cm}$, body weight $58.3 \pm 2.3 \mathrm{~kg}$, girth of chest $83.9 \pm 2.8 \mathrm{~cm}$, girth of right upper arm $25.0 \pm 1.6 \mathrm{~cm}$, arm span $167.9 \pm 2.3 \mathrm{~cm}$, and grasping power on right hand $40.7 \pm 3.2 \mathrm{~kg}$.

\section{Method}

\section{Exercise protocol}

A treadmill specially designed for wheelchair users was used in this study (Running Machine, product of Seno, Japan). Speed and inclination of the treadmill are adjustable in this equipment. A 4-wheel sportstype wheelchair was used for all of the participants to minimize the structural effect of wheelchair.

The model of the exercise is shown in Figure 1. The speed of the treadmill was fixed in $4.0 \mathrm{~km} / \mathrm{h}$. The inclination was increased by $0.5 \%$ every $5 \mathrm{~min}$ from $2.0 \%$ to $4.5 \%$. After wheelchair propulsion for $30 \mathrm{~min}$, the inclination was fixed at $3.0 \%$. This exercise protocol was the modified one used by Okuma $^{13}$ who evaluated the physical fitness of paraplegic athletes. In this program, a participant performed wheelchair propulsion for $3 \mathrm{~km}$ in $45 \mathrm{~min}$. 


\section{Measurements}

The heart rate was monitored during the exercise using a telegraphic electrocardiogram, to check for arrythmia and was recorded every $5 \mathrm{~min}$ at $1 \mathrm{~min}$ after newly increasing the inclination.

Blood samples were obtained before exercise, immediately after, $24 \mathrm{~h}$ after and $72 \mathrm{~h}$ after the exercise. The indwelling needles were kept patent by irrigation with heparinized saline solution and were used for sample collection in order to minimize pain from repeated needle insertions. Blood for biochemical analysis was centrifuged immediately after clotting, and the serum was frozen until assays were performed (except for LDH assay).

The blood cell count, electrolytes, total creatinekinase (CK) activity and isoenzyme composition, myoglobin $(\mathrm{Mb})$ concentration, total lactatedehydro-

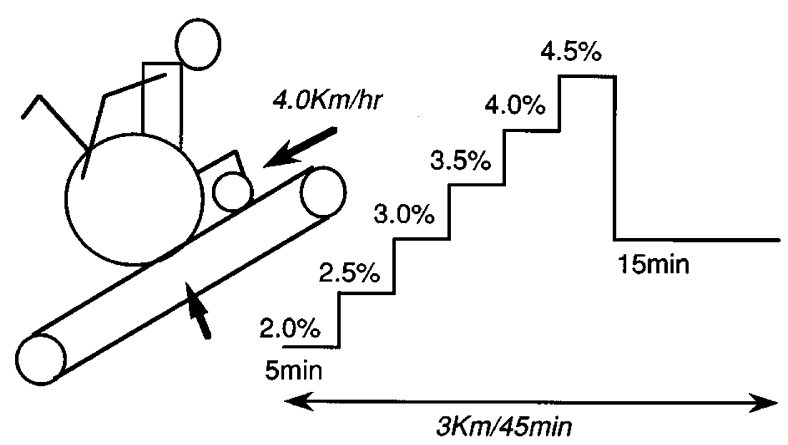

Figure 1 The model of exercise: speed of treadmill $4.0 \mathrm{~km} / \mathrm{h}$ increase of inclination by $0.5 \%$ every $5 \mathrm{~min}$ from $0.2 \%$ to $4.5 \%$ genase (LDH) activity and isoenzyme composition were measured with the commercially available laboratory kit. The normal value of these parameters in this kit were: total $\mathrm{CK}$ activity $57 \sim 197 \mathrm{IU} / \mathrm{L}, \mathrm{Mb}$ concentration $<60 \mathrm{ng} / \mathrm{ml}$, total LDH activity $230 \sim 460 \mathrm{IU} / \mathrm{L}$.

\section{Statistics}

The results are presented as mean \pm SD. The Paired Student's t-test was used to assess significance levels between pre-exercise and immediately, $24 \mathrm{~h}, 72 \mathrm{~h}$ afterexercise. Differences were considered significant when $P<0.05$.

\section{Results}

The change of heart rate at each inclination is shown in Figure 2. Arrythmias were not detected in any other participants.

No significant changes were observed in the electrolytes. The white blood cell and hematocrit were slightly increased immediately after the exercise (Table 1).

The value of CK-MM, which reflected the damage of striated muscle, was estimated from the total $\mathrm{CK}$ activity and isoenzyme composition. The mean of CKMM was normal prior to the exercise, and remarkably increased after the exercise reaching a peak value at $24 \mathrm{~h}$ after the exercise (Figure 3 ).

The mean of myoglobin $(\mathrm{Mb})$ concentration was normal prior to exercise, and increased gradually (Figure 4). The value at $24 \mathrm{~h}$ after and $72 \mathrm{~h}$ after exercise showed significance.

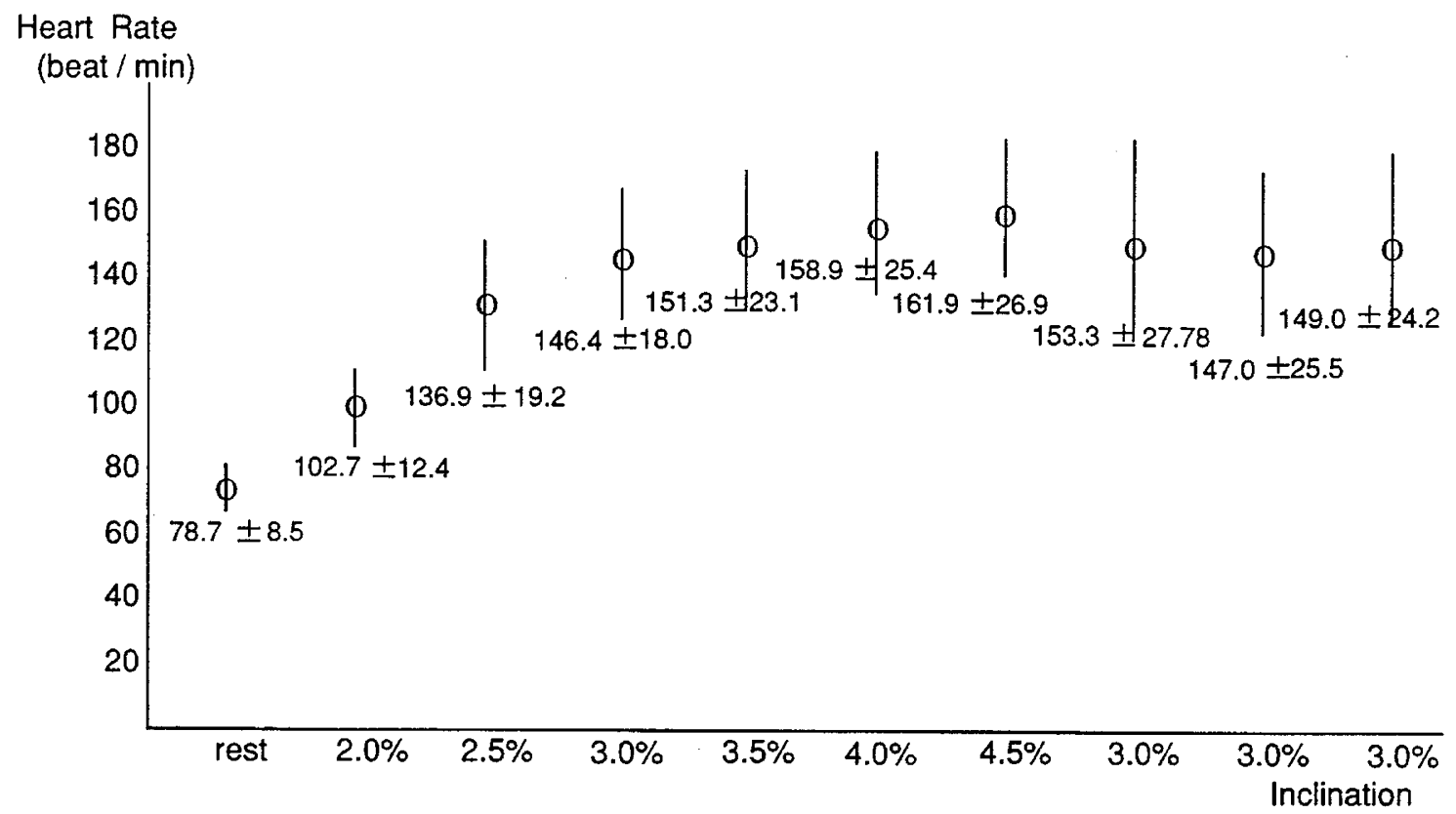

Figure 2 The change of heart rate 
Table 1 Electrolytes and blood cells studies

\begin{tabular}{|c|c|c|c|c|}
\hline & Pre-ex & Immed-after & 24 h-after & 72 h-after \\
\hline $\mathrm{Na}$ & $139.9 \pm 2.1$ & $139.4 \pm 2.4$ & $139.6 \pm 1.0$ & $139.6 \pm 0.5$ \\
\hline $\mathrm{K}$ & $3.8 \pm 0.1$ & $4.0 \pm 0.3$ & $3.9 \pm 0.2$ & $4.0 \pm 0.2$ \\
\hline $\mathrm{Cl}$ & $101.4 \pm 2.6$ & $100.3 \pm 2.0$ & $102.7 \pm 1.4$ & $103.6 \pm 1.8$ \\
\hline WBC & $5185.7 \pm 942.4$ & $6328.6 \pm 1481.8$ & $5485.7 \pm 1132.0$ & $6071.4 \pm 1924.2$ \\
\hline $\mathrm{Hb}$ & $15.0 \pm 0.5$ & $15.8 \pm 0.5$ & $14.7 \pm 0.6$ & $14.1 \pm 0.6$ \\
\hline Hct & $45.6 \pm 2.1$ & $47.9 \pm 2.3$ & $43.3 \pm 2.0$ & $42.9 \pm 2.4$ \\
\hline
\end{tabular}

Data are shown as mean \pm S.D. $n=7$

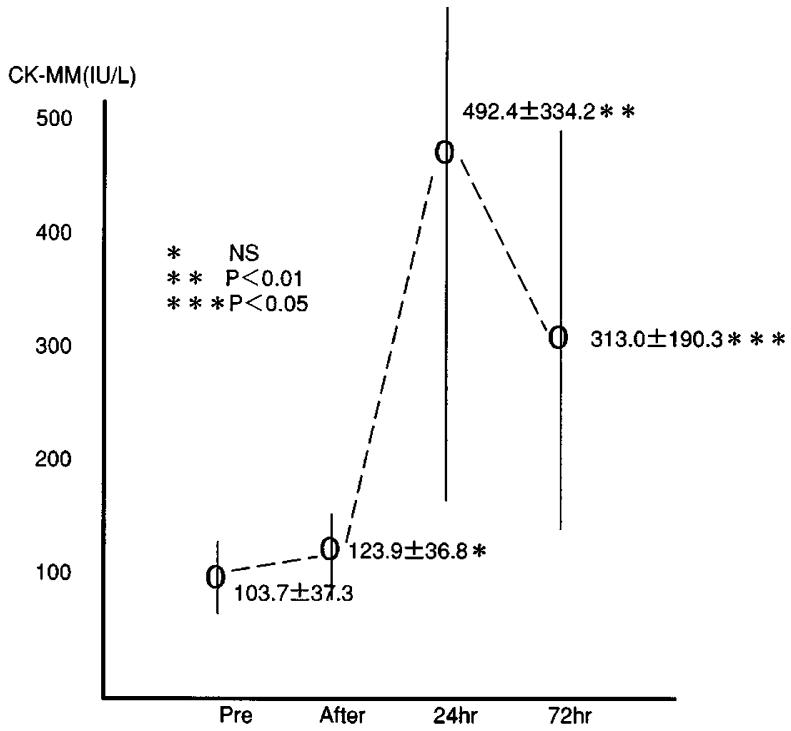

Figure 3 The change of CK-MM: estimated from the total $\mathrm{CK}$ activity and isoenzyme composition significantly increased $24 \mathrm{~h}$-after and $72 \mathrm{~h}$-after the peak value was observed 24 h-after

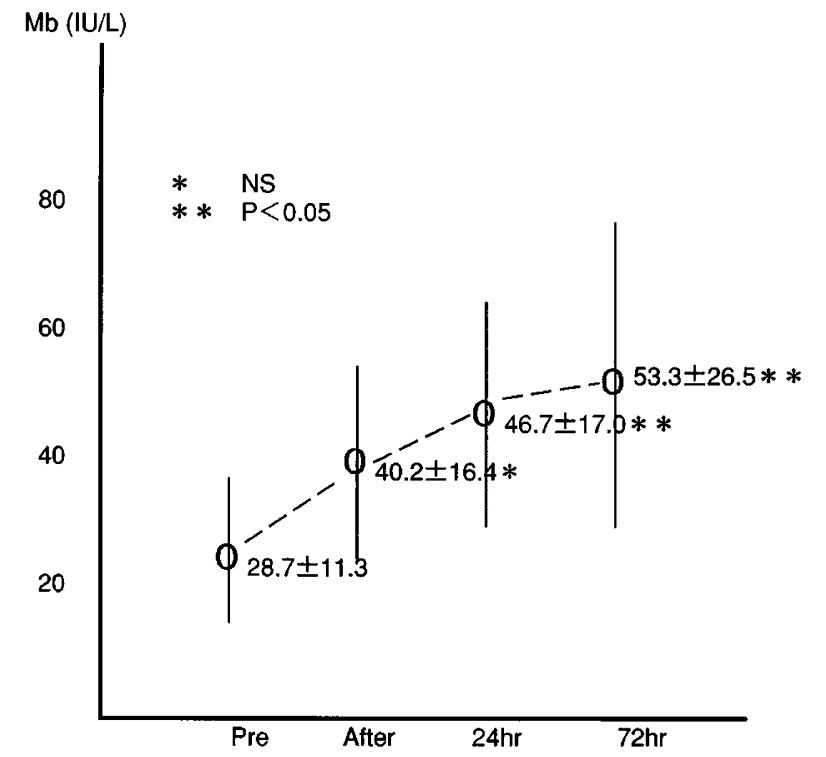

Figure 4 The change of $\mathrm{Mb}$ : significantly increased $24 \mathrm{~h}$-after and 72 -after the peak value was observed $72 \mathrm{~h}$-after

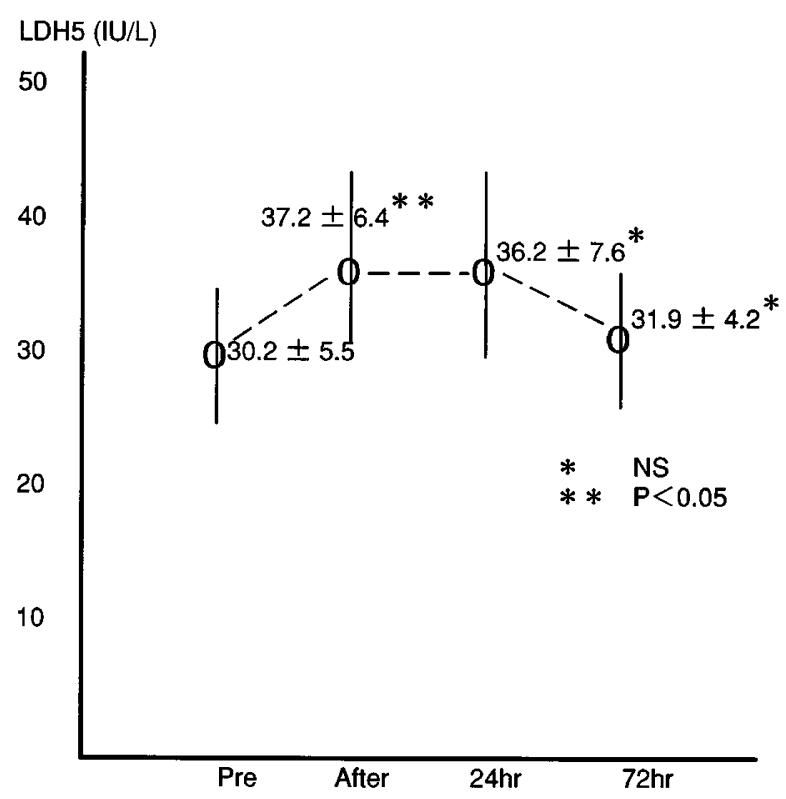

Figure 5 The change of $\mathrm{LDH}_{5}$ : estimated from the total LDH activity and isoenzyme composition significantly increased immediately-after only

The value of $\mathrm{LDH}_{5}$ which reflected the damage of striated muscle was estimated from the total LDH activity and isoenzyme composition. The mean of $\mathrm{LDH}_{5}$ was normal prior to exercise, and increased slightly but significantly after the exercise (Figure 5). It reached the peak value immediately after the exercise.

\section{Discussion}

Considering the mean age of subjects, the age-predicted maximum heart rate is nearly 195 beats/min and 'training-sensitive zone' $(70 \% \sim 90 \%$ of maximum heart rate) can be estimated as $136-175$ beats $/ \mathrm{min} .{ }^{14}$ Regarding cardiovascular fitness, the protocol used in this study may be recognized as being 'moderate exercise' (Figure 2).

The increased hematocrit immediately following the exercise indicated the possibility of hemoconcentration caused by dehydration (Table 1). The elevations of myoglobin $(\mathrm{Mb})$ and enzymes $\left(\mathrm{CK}-\mathrm{MM}, \mathrm{LDH}_{5}\right)$ were significant (Figure 3-5). Although some of these 
elevations may have been due to hemoconcentration or by decreased renal clearance, the existence of skeletal muscle damage was clearly suggested.

It is quite difficult to describe which muscles were mainly damaged in this exercise protocol. Muscles in the arms would be the first to be reflected, but the possibility of muscle damage in the trunk and legs remains because able-bodied subjects tend to stabilize their trunk using these muscles in the wheelchair. Isometric or concentric contraction of these muscles can be carried out easily even when in a wheelchair, and the increased inclination in this exercise protocol would require a more rigidly stabilized trunk than would be necesssary for propulsion on level ground.

The time-courses of parameters measured in this study were different from other studies. $\mathrm{LDH}_{5}$ reached its peak value immediately after the exercise and CKMM was reached $24 \mathrm{~h}$ later (Figure 3 and 5). But myoglobin increased gradually during the study (Figure 4). Many authors reported the time-course of these parameters stating: myoglobin reached the peak value immediately after the exercise and $\mathrm{CK}$ reached $24 \mathrm{~h}$ after. ${ }^{1,8,9}$

The molecule size of these parameters should be considered when we discuss their time-course. Because the increase of these parameters reflects/focal necrosis of muscle fibers, ${ }^{15}$ the 'smaller' protein may appear in the blood earlier through a smaller lesion in the sarcolemma. The molecular weights of these parameters are: CK-MM 85,000 daltons, ${ }^{16} \mathrm{LDH}_{5}$ $135,000,{ }^{16}$ myoglobin 17,500 daltons. ${ }^{17}$ It is reasonable to expect that myoglobin reaches the peak value first, CK-MM and $\mathrm{LDH}_{5}$ follow.

The reason for the inconsistency between our results and this theory is somewhat unclear. The author would suggest one possibility. Most former studies have dealt with rather simplified exercise for healthy subjects, for example elbow bending exercise and down-hill running. However, in our study, no subject had experience of wheelchair propulsion. They were allowed to propel their wheelchairs without any regulation of propulsion form. It means that the variance of the muscles used in the protocol is quite large. Some subjects complained of neck muscle pain after the exercise, but others had pain in their shoulders or upperarms. The large variance may have been brought about by the time discrepancy and the extent discrepancy of the muscles damaged in the exercise. The time-course of enzymes described above appears to substantiate this.

This study suggests that wheelchair propulsion cause muscle damage in the able-bodied in certain conditions. The neurologically handicapped person such as someone with a severe spinal cord injury can be considered to damage residual functions easily. There is a report in which the high incidence of overuse injuries in wheelchair racing athletes was described. ${ }^{18}$ Rehabilitation professionals should always be concerned about the possibility of muscle damage caused by wheelchair propulsion, not only in relation to sports activities, but also from other daily activities.

\section{References}

1 Iwane H. A follow up study of changes in serum myoglobin and enzyme levels in Japanese triathletes. Annals of Sports Medicine 1987; 3: $139-143$.

2 Farber HW et al. The endurance triathlon: metabolic changes after each event and during recovery. Med Sci Sports Exerc 1991; 23: $959-965$

3 Apple FS, Rhodes M. Enzymatic estimation of skeletal muscle damage by analysis of changes in serum creatine kinase. $J$ Appl Physiol 1988; 65: 2598-2600.

4 Clarkson PM, Nosaka K, Brown B. Muscle function after exercise-induced muscle damage and rapid adaptation. Med Sci Sports Exerc 1992; 24: 512-520.

5 Hagberg M. Muscular endurance and surface electromyogram in isometric and dynamic exercise. J Appl Physiol 1981; 51: 1-7.

6 Nosaka K, Clarkson PM. Relationship between post-exercise plasma CK elevation and muscle mass involved in the exercise. Int J Sports Med 1992; 13: 471 - 475.

7 Newham DF, Jones DA, Clarkson PM. Repeated high-force eccentric exercise: effects on muscle pain and damage. $J$ Appl Physiol 1987; 63: $1381-1386$.

8 Byrnes WC, Clarkson PM, White JS. Delayed onset muscle soreness following repeated bouts of downhill running. $\mathrm{J} \mathrm{Appl}$ Physiol 1985; 59: $710-715$.

9 Balnave CD, Thompson MW. Effect of training on eccentric exercise-induced muscle damage. J Appl Physiol 1993; 75: $1545-$ 1551.

10 Apple FS et al. Creatinekinase-MB isoenzyme adaptation in stressed human skeletal muscle of marathon runners. $J \mathrm{Appl}$ Physiol 1985; 59: 149-153.

11 Evans WJ et al. Metabolic changes following eccentric exercise in trained and untrained men. J Appl Physiol 1986; 61: 1864-1868.

12 Rodgers MM, Gayle GW, Figoni SF, Kobayashi M. Biomechanics of wheelchair propulsion during fatigue. Arch Phys Med Rehabil 1994; 75: 85-93.

13 Okuma H, Ogata H, Hatada K. Transition of physical fitness in wheelchair marathon competitors over several years. Paraplegia 1989; 27: $237-243$

14 McArdle W, Katch F, Katch V. Training for anaerobic and aerobic power. In: McArdle W(ed). Exercise Physiology, 3rd ed. Lea and Febiger 1991, pp 423-451.

15 Schmalbruch H, Oksche A, Vollrath L. Development, Regeneration, Growth. In: Schmalbruch H (ed) Handbook of Microscopic Anatomy Vol II/6: Skeletal Muscle. Springer-Verlag 1995, pp $239-303$.

16 Moss DW. Enzymes In: Burtis C(ed) Tietz Textbook of Clinical Chemistry. 2nd edn. WB Saunders 1994, pp 735-896.

17 Chen IW. Myoglobin In: Pesce AJ (ed) Methods in Clinical Chemistry CV Mosby 1987, pp 917-921.

18 Taylor D, Williams T. Sports injuries in athletes with disabilities; wheelchair racing. Paraplegia 1995; 33: 296-299. 